\title{
Osteogenesis imperfecta and combined orthodontics and orthognathic surgery: a case report on two siblings
}

\author{
Dong-Young Kim¹, Unbong Baik², Ju-Hong Jeon ${ }^{1}$ \\ ${ }^{l}$ Department of Oral and Maxillofacial Surgery, Asan Medical Center, ${ }^{2}$ Private Clinic, Seoul, Korea
}

\begin{abstract}
J Korean Assoc Oral Maxillofac Surg 2020;46:70-77)
Osteogenesis imperfecta is a heterogeneous group of connective tissue diseases that is predominantly characterized by bone fragility and skeletal deformity. Two siblings with undiagnosed type I osteogenesis imperfecta underwent orthognathic surgery for the treatment of facial asymmetry and mandibular prognathism. The authors report two cases of combined orthodontics and orthognathic surgery in patients with type I osteogenesis imperfecta, mandibular prognathism, and facial asymmetry.
\end{abstract}

Key words: Osteogenesis imperfecta, Orthognathic surgery

[paper submitted 2019. 7. 10 / revised 2019. 8. 23 / accepted 2019. 9. 11]

\section{Introduction}

Osteogenesis imperfecta (OI), also known as brittle bone disease, is a heterogeneous group of connective tissue diseases that is predominantly characterized by bone fragility and skeletal deformity ${ }^{1}$. Most cases of OI are associated with autosomal dominant mutations in the two type I collagen genes (COL1A1 on chromosome 17 and COL1A2 on chromosome $7)^{2-4}$. Collagen is the most abundant protein in the body and comprises the connective tissue in cartilage, bone, and blood vessels. In addition, there are 19 types of collagen, and type I collagen, the most common, provides mechanical strength ${ }^{5}$.

OI has a birth prevalence of approximately 1:20,000. However, a significant number of patients are undiagnosed, possibly due to lack of awareness, absence of severe symptoms, or other reasons.

Sillence et al. ${ }^{1}$ classified OI based on clinical presentation and pattern of inheritance into types I to IV, and the classifi-

\section{Ju-Hong Jeon \\ Department of Oral and Maxillofacial Surgery, Asan Medical Center, 88 Olympic-ro 43-gil, Songpa-gu, Seoul 05505, Korea \\ TEL: +82-2-3010-3850 FAX: +82-2-3010-6967 \\ E-mail:mfsijh@unitel.co.kr \\ ORCID: https://orcid.org/0000-0003-4730-1102}

(c) This is an open-access article distributed under the terms of the Creative Commons Attribution Non-Commercial License (http://creativecommons.org/ licenses/by-nc/4.0/), which permits unrestricted non-commercial use, distribution, and reproduction in any medium, provided the original work is properly cited.

Copyright (C) 2020 The Korean Association of Oral and Maxillofacial Surgeons. All rights reserved. cation system is the most widely used.(Table 1) Patients with the typically-milder type I (mild) and IV (mild-to-moderate) present with bone fragility and, at times, dentinogenesis imperfecta and some hearing loss. In type I, the sclera is usually blue and/or stature is normal, but in type IV, the sclera is normal while stature is variably short. Types II (lethal, perinatal type) and III (progressively deforming type) are more severe and often associated with extreme bone fragility. Perinatal death with under-mineralized skull and micromelic bone is frequent in type II, whereas in type III, patients have moderate deformity of the limbs at birth and, oftentimes, very short stature and dentinogenesis imperfecta ${ }^{1}$.

Like other organs containing type I collagen, the cranial bones are also affected by OI. Many studies have reported that the intermaxillary relationship in patients with OI has a Class III tendency with a posterior open bite and an anterior posterior crossbite ${ }^{6-10}$. An abnormal jaw relationship was especially found in patients with types III and IV OI. On the other hand, some studies have reported that patients with type I OI do not show a severe abnormality of the intermaxillary relationship, although the size of the facial bones is smaller than normal linear measurements ${ }^{10}$.

Few cases of orthognathic surgery in patients with OI have been reported, but most describe successful operations ${ }^{5,11-13}$. In this report, we present two patients (siblings) with type I OI. During the course of treatment for the younger sister, the disease was not recognized until abnormal extensive ecchy- 
mosis occurred in the early postoperative period. Because we detected OI during the first operation for the younger sister, we were able to carefully prepare for the older sibling's operation.

\section{Cases Report}

\section{Case 1}

A 31-year-old female patient was referred by her orthodontist to Asan Medical Center in Seoul, Korea for treatment of facial asymmetry and prognathism. The patient had never been diagnosed with a medical problem and had no previous history of fracture. Clinical examination revealed that the patient was slightly short in height $(153.4 \mathrm{~cm})$ and moderately overweight (62.4 kg, body mass index [BMI] $\left.26.52 \mathrm{~kg} / \mathrm{m}^{2}\right)$. Examination of her facial features revealed a long lower face with vertical maxillary excess and mandibular asymmetry with occlusal canting of the maxilla. In addition, she had upper lip protrusion and lip incompetence.(Fig. 1, 2) The intraoral findings included Class III malocclusion with an open

Table 1. Sillence's classification of osteogenesis imperfecta

\begin{tabular}{cc}
\hline Type & Characteristic \\
\hline I & $\begin{array}{c}\text { Mild form, normal stature, minimal or no deformity, } \\
\text { fragile bone, blue sclera, hearing loss, and autosomal } \\
\text { dominant and recessive inheritance } \\
\text { II } \quad \begin{array}{c}\text { Severe and perinatally lethal type, poor cranial min- } \\
\text { eralization, fragile bone, severe long bone deformity, and }\end{array} \\
\text { autosomal dominant inheritance }\end{array}$ \\
III $\quad \begin{array}{c}\text { Deforming type, fragile bone and long bone deformities, } \\
\text { short stature, sclera variable in color, dentinogenesis } \\
\text { imperfecta and hearing loss common, and autosomal } \\
\text { dominant and recessive inheritance } \\
\text { Mildly deforming, variable short stature, fragile bone, } \\
\text { normal sclera, dentinogenesis imperfecta common, hea- } \\
\text { ring loss variable, and autosomal dominant inheritance }\end{array}$ \\
\hline
\end{tabular}

Dong-Young Kim et al: Osteogenesis imperfecta and combined orthodontics and orthognathic surgery: a case report on two siblings. J Korean Assoc Oral Maxillofac Surg 2020 bite. She had normal tooth structure and received proper dental care. Therefore, her periodontal health and oral hygiene were good.

After the initial interview, the patient was referred to an orthodontist for leveling and alignment of the teeth, and treatment continued for approximately one year. After the presurgical orthodontic treatment, a clinical evaluation was repeated, and cephalometric radiographs and face bow recordings were obtained for final surgical planning 4 weeks prior to the surgery.

In addition, a work-up for general anesthesia and surgery was performed, and the preoperative hematologic examination, electrocardiogram and chest radiograph were unremarkable.

The surgery included bimaxillary procedures. Le Fort I osteotomy with midline correction, canting correction, posterior impaction, and setback movement of the maxilla were performed via rigid skeletal fixation. Bilateral sagittal split ramus osteotomies were performed with a setback movement via the hybrid fixation technique (with one miniplate and one additional bicortical screw). On the left side, a greenstick fracture occurred in the proximal segment. However, we could appropriately position the proximal and distal segments as planned, and so two additional bicortical screws were used to fix the fractured proximal segment. Two closed suction drains were inserted into the mandibular surgical site. The operation was completed without major bleeding, and the estimated blood loss during the surgery was $200 \mathrm{~mL}$.

Abnormal edema and ecchymosis were observed from the second postoperative day.(Fig. 3) At first, an improperly functioning closed suction drain was suspected, but the ecchymosis and edema appeared to be bilateral, decreasing the likelihood of drain malfunction. On the second postoperative day, drain removal and maxilla-mandibular fixation (MMF) with elastic ring were routinely performed. Normally, an or-
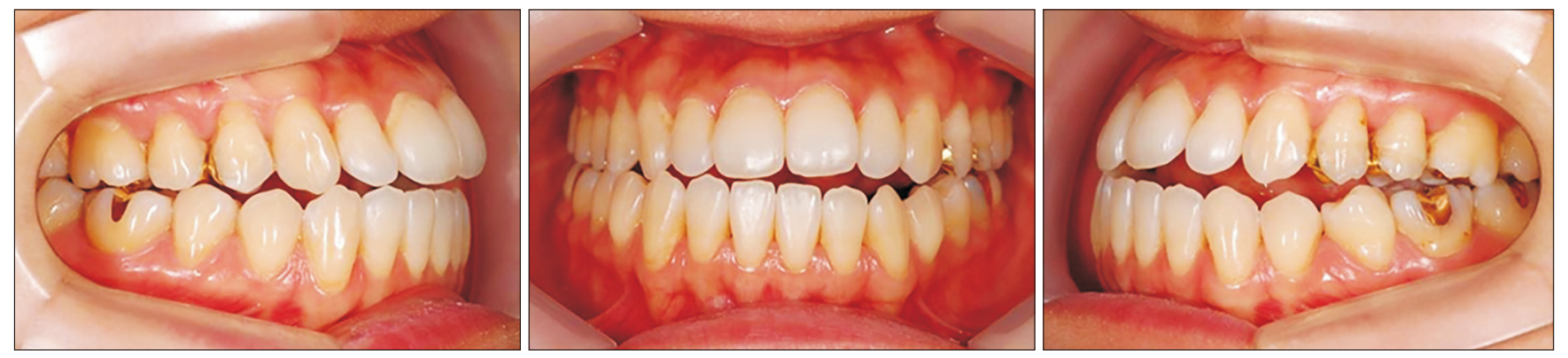

Fig. 1. Preoperative intraoral photographs of Case 1 patient.

Dong-Young Kim et al: Osteogenesis imperfecta and combined orthodontics and orthognathic surgery: a case report on two siblings. J Korean Assoc Oral Maxillofac Surg 2020 

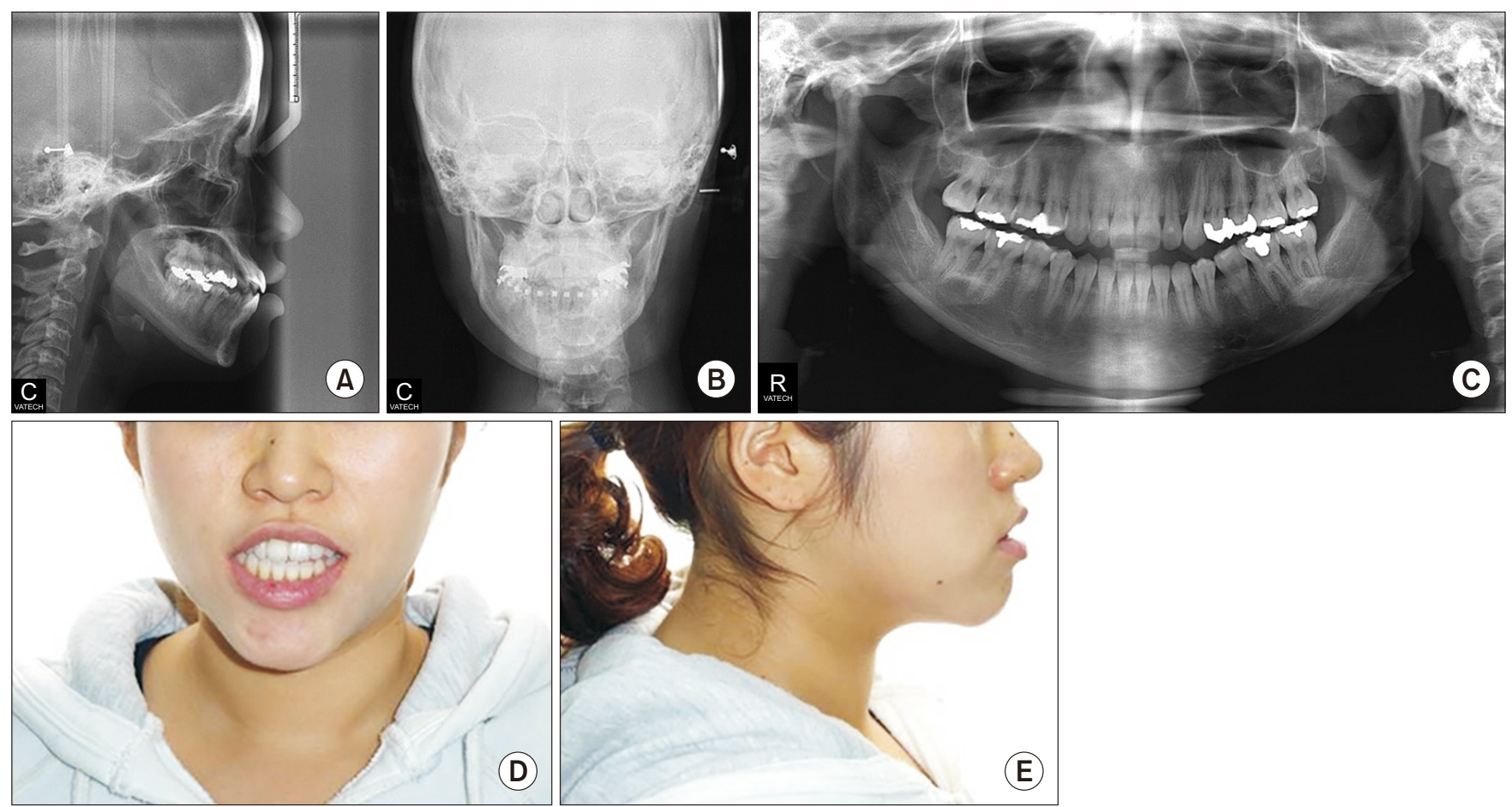

Fig. 2. Preoperative cephalometric (A, B), panoramic (C), and facial views (D, E) of Case 1 patient.

Dong-Young Kim et al: Osteogenesis imperfecta and combined orthodontics and orthognathic surgery: a case report on two siblings. J Korean Assoc Oral Maxillofac Surg 2020
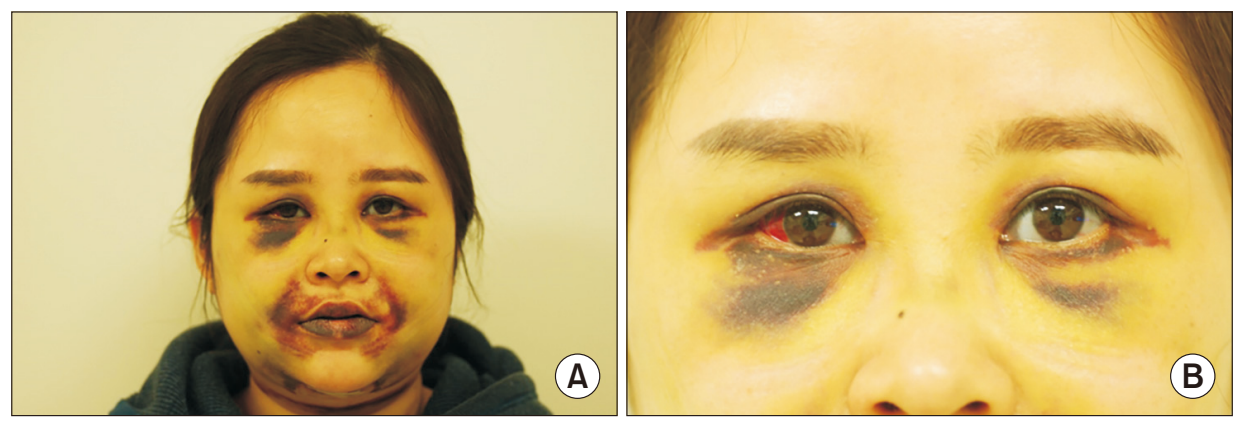

Fig. 3. Photographs on postoperative 9 days of Case 1 patient; Ecchymosis and abnormal edema (A), subconjunctival hemorrhage, blue sclera $(\mathrm{B})$.

Dong-Young Kim et al: Osteogenesis imperfecta and combined orthodontics and orthognathic surgery: a case report on two siblings. $J$ Korean Assoc Oral Maxillofac Surg 2020 thognathic surgical patient is hospitalized for 2 nights and 3 days after surgery, but in this case, the discharge was delayed due to the appearance of abnormal ecchymosis and edema. On the fifth postoperative day, nasal bleeding and transient blood pressure lowering were noted, but the problems resolved after nasal packing and administration of intravenous fluids. At 6 days postoperatively, the patient was stable, and she was discharged from the hospital.

MMF was routinely stopped 2 weeks after surgery, and training elastics were applied. No other complications were observed. However, the ecchymosis persisted for 6 weeks, and although it dissipated slowly and spontaneously, no specific treatment was needed for its resolution. The follow-up examination at postoperative 3 months showed uneventful healing.
During the search for the cause of unexpected postoperative bleeding, she recounted multiple fractures of the lower limbs during childhood, and blue sclera was noticed. Furthermore, her familial history included multiple bone fractures in her mother, grandmother, and cousin. Therefore, OI type I was suspected, and it was inferred that the patient's complications were ultimately caused by bleeding due to vessel fragility from OI.

The postsurgical orthodontic treatment began one month after surgery. The molar and canine relation became Class I, and the open bite was greatly improved. After approximately eight months, debonding was done. The long lower face with vertical maxillary excess and mandibular asymmetry with occlusal canting of the maxilla were greatly improved. The upper lip protrusion and lip incompetence were also 
improved.(Fig. 4, 5)

\section{Case 2}

A 33-year-old female patient was referred by her orthodontist to Asan Medical Center in Seoul, Korea for the treatment of facial asymmetry and chin protrusion. She was the older sister of the patient from Case 1, and she appeared similar to her younger sister.

The patient also had never been previously diagnosed with a medical problem, but she did have a history of sur- gery for a left leg bone fracture in her teenage years. The general examination revealed that the patient was slightly short in height $(155.0 \mathrm{~cm})$ and slightly overweight $(52.8 \mathrm{~kg}$, BMI $21.98 \mathrm{~kg} / \mathrm{m}^{2}$ ), similar to her younger sister.

As for her facial features, the patient had a facial appearance similar to her sister's, and she had the following similar problems. She had a long lower face with vertical maxillary excess and mandibular asymmetry with occlusal canting and yawing of the maxilla. Upper lip protrusion and chin protrusion were also apparent.(Fig. 6,7) Intraoral findings included Class III malocclusion with a shallow
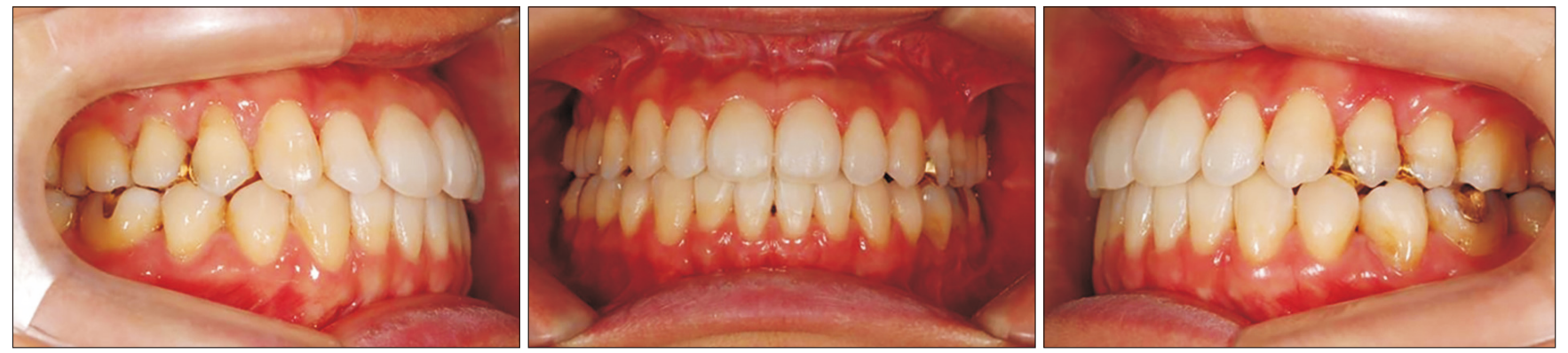

Fig. 4. Intraoral photographs on debonding of Case 1 patient.

Dong-Young Kim et al: Osteogenesis imperfecta and combined orthodontics and orthognathic surgery: a case report on two siblings. J Korean Assoc Oral Maxillofac Surg 2020

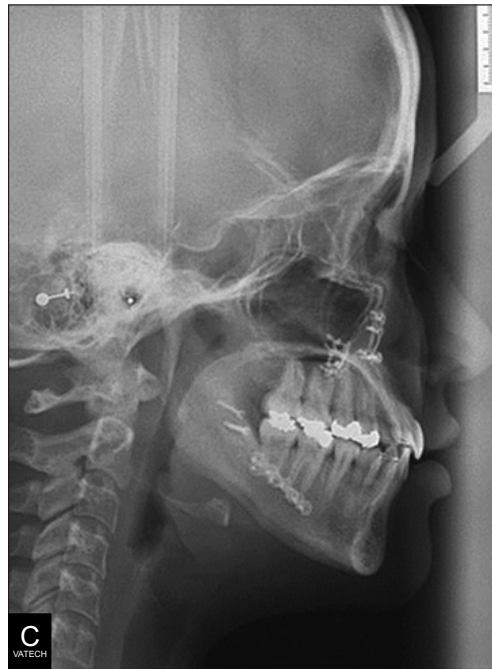

(A)

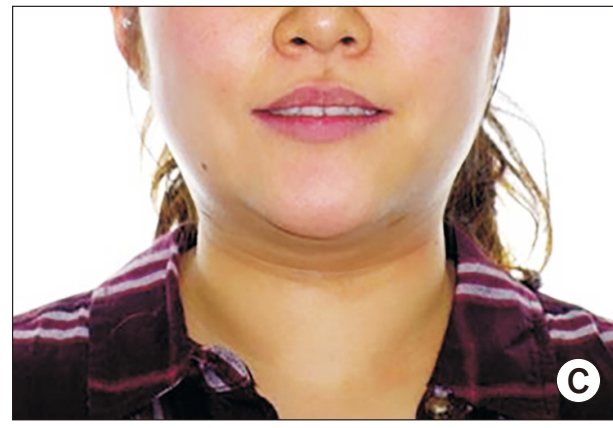

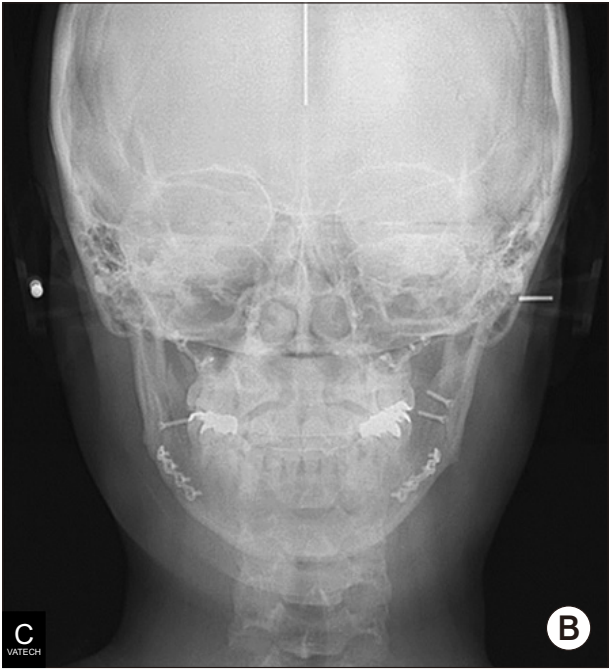

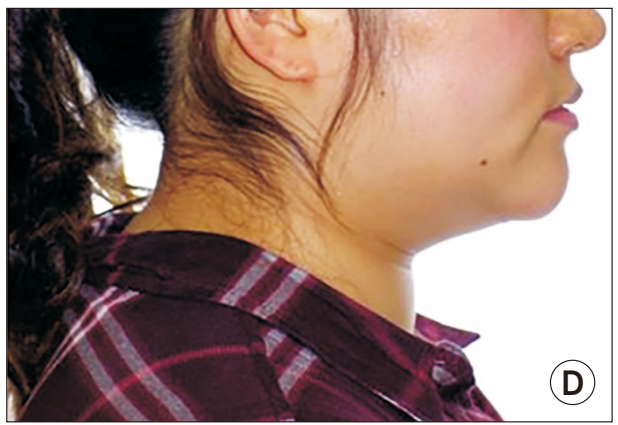

Fig. 5. Cephalometric (A, B) and facial views $(C, D)$ on debonding of Case 1 patient.

Dong-Young Kim et al: Osteogenesis imperfecta and combined orthodontics and orthognathic surgery: a case report on two siblings. $J$ Korean Assoc Oral Maxillofac Surg 2020 

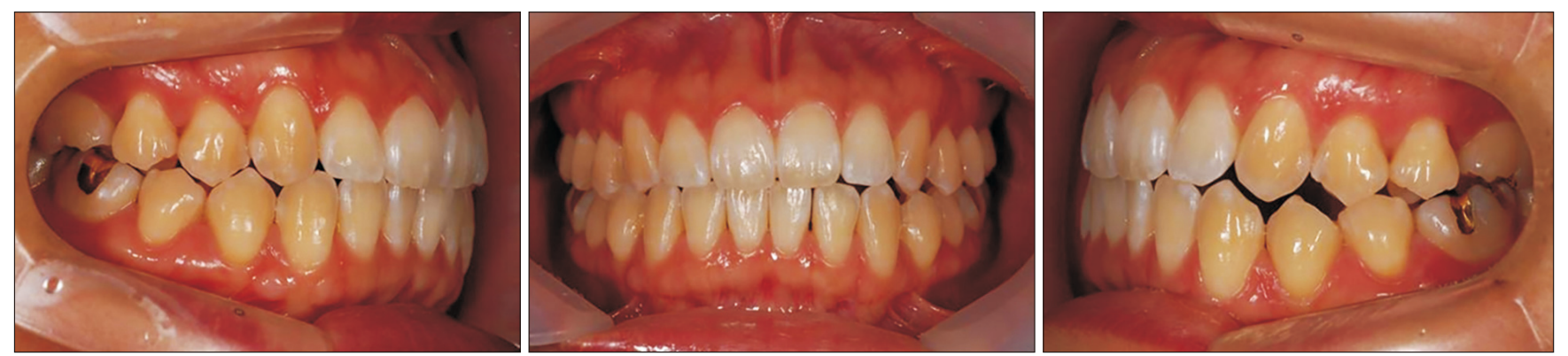

Fig. 6. Preoperative intraoral photographs of Case 2 patient.

Dong-Young Kim et al: Osteogenesis imperfecta and combined orthodontics and orthognathic surgery: a case report on two siblings. J Korean Assoc Oral Maxillofac Surg 2020
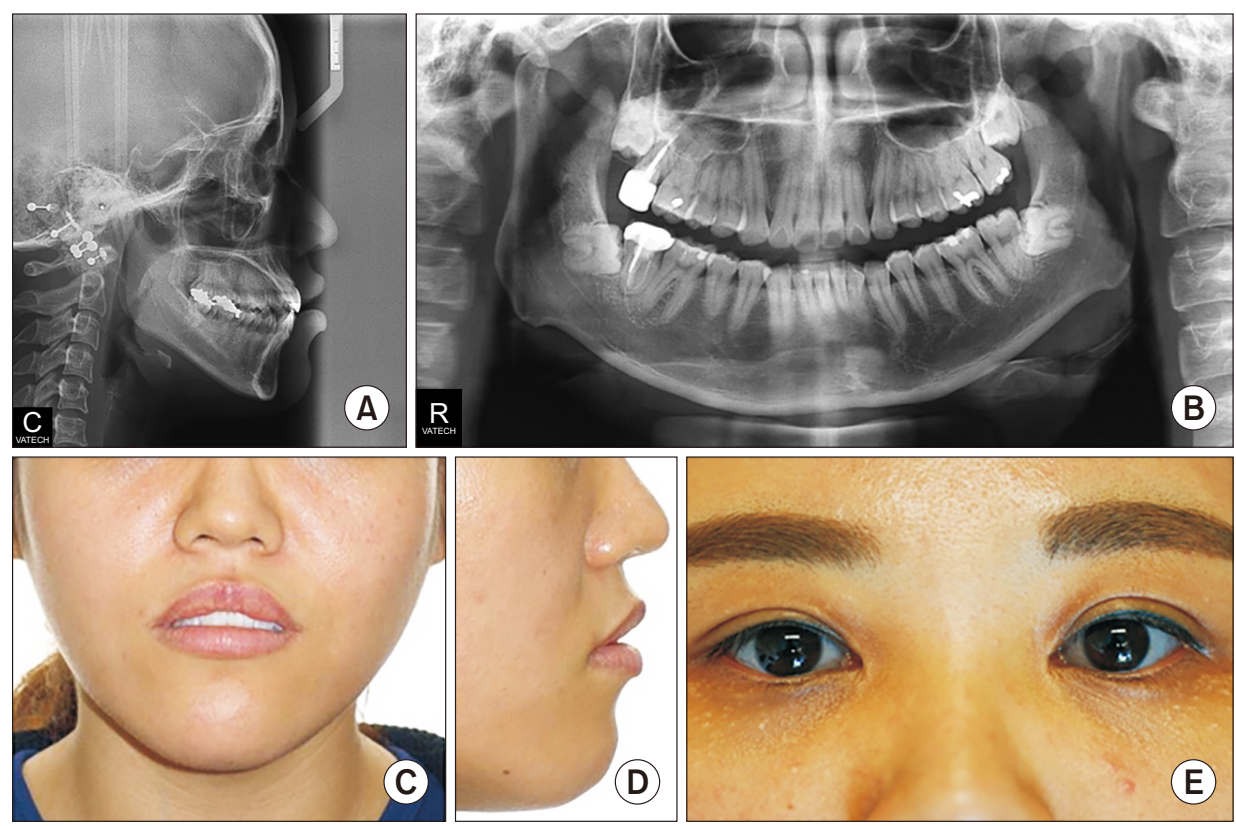

Fig. 7. Preoperative cephalometric $(A)$, panoramic $(B)$, and facial views $(C, D)$ of Case 2 patient and her blue sclera (E) can be seen.

Dong-Young Kim et al: Osteogenesis imperfecta and combined orthodontics and orthognathic surgery: a case report on two siblings. J Korean Assoc Oral Maxillofac Surg 2020

overbite. Likewise, she had normal teeth structure, and she also had good periodontal health and oral hygiene due to proper dental care.

She was referred to the same orthodontist as her sister for one year of orthodontic treatment before surgery. After the presurgical orthodontic treatment, the clinical evaluation was repeated, and cephalometric radiographs and face bow recordings were obtained for final surgical planning 4 weeks prior to the surgery.

In addition, a work-up for general anesthesia and surgery were performed, and all results were normal. However, during the patient's surgical preparation, OI was critically considered due to her family history and her younger sister's operative complications.

The possibility of hemorrhage due to OI was explained to the patient prior to surgery. Furthermore, we noted that the operation could be stopped and changed to a two-step pro- cedure if massive bleeding occurred during surgery.

The surgical plan was similar to that of the patient from Case 1 as the sisters had similar craniofacial relationships. The surgery included bimaxillary procedures. Le Fort I osteotomy with midline correction, canting correction, posterior impaction, and setback movement of the maxilla were performed using rigid skeletal fixation. Bilateral sagittal split ramus osteotomies were performed with a setback movement using the hybrid fixation technique (one miniplate and one additional bicortical screw). On the left side, a greenstick fracture occurred in the proximal segment, as in the younger sister's case, but we could appropriately position the proximal and distal segments as planned, and so two additional bicortical screws were used to fix the fractured proximal segment. Two closed suction drains were inserted into the mandibular surgical site. The operation was completed without major bleeding, and the blood loss dur- 
ing the surgery was estimated to $200 \mathrm{~mL}$.

The patient's recovery process proceeded routinely, and there was no remarkable finding. Daily dressing was done, and on the second postoperative day, drain removal and MMF with elastic ring were performed. On the third postoperative day, the patient was discharged without any abnormal complications.

MMF was stopped 2 weeks after surgery, and training elastics were applied. No other complications were observed. The follow-up examination at postoperative 6 months showed uneventful healing.

The postsurgical orthodontic treatment began one month after surgery. After Class I molar, canine relationship, normal overbite and overjet were achieved, debonding was done. The patient's long lower face with vertical maxillary excess and mandibular asymmetry with occlusal canting and yawing of the maxilla were greatly improved. Upper lip protrusion and chin protrusion were also improved.(Fig. 8, 9) No specific problems during orthodontic treatment were encountered.

\section{Discussion}

A significant number of patients with OI remain undiagnosed. Initially, we did not consider the existence of an un- derlying medical problem in the present cases. However, after orthognathic surgery for the first patient (younger sister), we speculated the cause of abnormal bleeding. Thereafter, we confirmed the diagnosis of OI type I in both cases based on the typical clinical features of OI, such as multiple bone fracture history, short stature, blue sclera, the bleeding episode during the younger sister's orthognathic surgery and familial history; we did not base the diagnosis on laboratory findings.

Most orthognathic surgeries for patients with OI have reported acceptable outcomes. The risk of perioperative bleeding in patients with OI should be very carefully considered, and some authors reported patients with OI and severe bleeding during or after orthognathic surgery ${ }^{14-16}$. The patient in the first case showed abnormal edema and ecchymosis after surgery, despite normal blood test results. This appears to be due to vessel fragility in patients with OI and has been reported previously ${ }^{17}$. A Rosén et al. ${ }^{5}$ reported that orthognathic surgery in patients with OI had been considered as a two-step procedure in cases of severe bleeding. In our cases, this method was considered for the second patient after the unfavorable recovery of the first patient. Fortunately, there was no abnormal bleeding in the second case, and bimaxillary surgery was executed as initially planned.

Several authors reported poor bone quality in patients
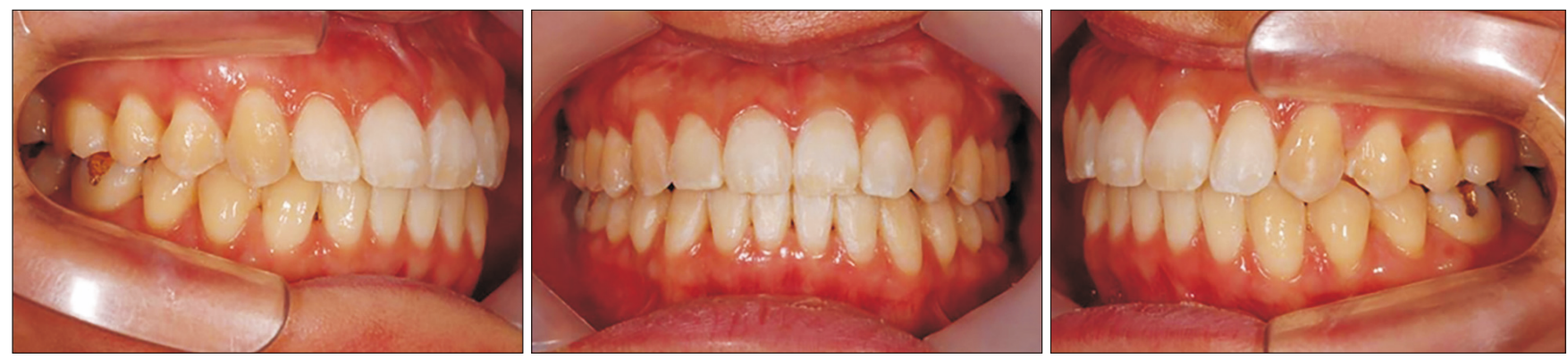

Fig. 8. Intraoral photographs on debonding of Case 2 patient.

Dong-Young Kim et al: Osteogenesis imperfecta and combined orthodontics and orthognathic surgery: a case report on two siblings. J Korean Assoc Oral Maxillofac Surg 2020
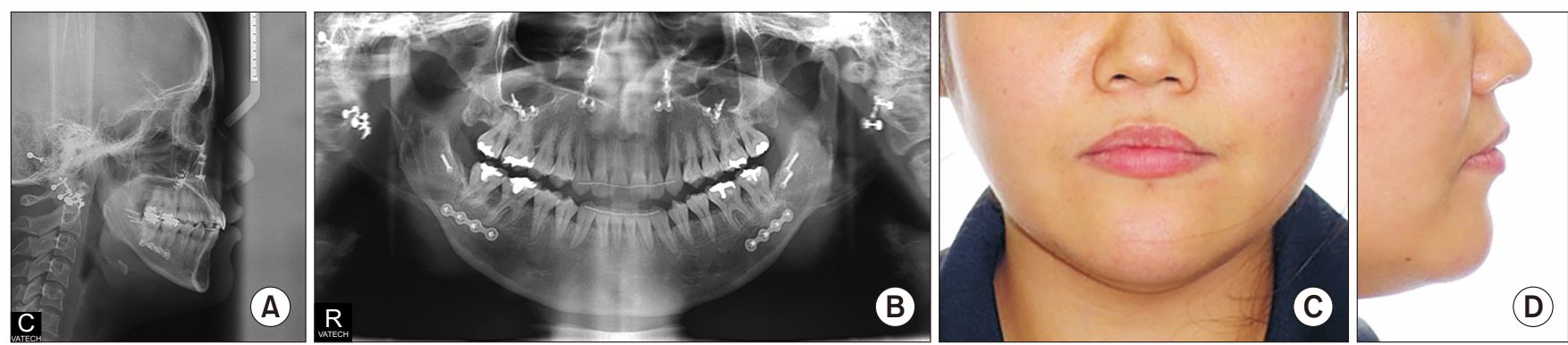

Fig. 9. Cephalometric (A), panoramic (B), and facial views (C, D) of Case 2 patient.

Dong-Young Kim et al: Osteogenesis imperfecta and combined orthodontics and orthognathic surgery: a case report on two siblings. J Korean Assoc Oral Maxillofac Surg 2020 
with $\mathrm{OI}^{5,12}$. Moreover, Tashima et al. ${ }^{12}$ reported that he changed his plan and would only perform mandibular orthognathic surgery in cases that need bimaxillary orthognathic surgery, and he suggested prolonged intermaxillary fixation to facilitate bone union due to poor bone quality in a patient with OI. In our cases, the patients' bone quality was somewhat poor, but fortunately, internal fixation was possible. Many authors reported normal bone healing patterns after orthognathic surgery in patients with OI, and similarly, normal recovery patterns were observed in our cases.

Many cases of successful orthodontic treatment have been reported in patients with OI, some of whom additionally had dentinogenesis imperfecta ${ }^{5,11,12,18}$. As with bone healing and remodeling after orthognathic surgery, the process following orthodontic treatment was considered successful. One consideration, however, is that some patients with OI may have been using bisphosphonates to reduce fractures ${ }^{19,20}$. Therefore, if patients with OI require tooth extraction for orthodontic treatment and orthognathic surgery, clinicians should consider medication-related osteonecrosis of the jaw (MRONJ) and investigate the history of bisphosphonate drug treatment.

In conclusion, for patients with OI, an abnormal healing process may occur after surgery due to vessel fragility. Furthermore, other various abnormal complications may occur. Therefore, cases involving patients with OI should be carefully evaluated in many respects prior to the actual surgery.

\section{ORCID}

Dong-Young Kim, https://orcid.org/0000-0002-2772-2519

Unbong Baik, https://orcid.org/0000-0002-9038-9229

Ju-Hong Jeon, https://orcid.org/0000-0003-4730-1102

\section{Authors' Contributions}

D.Y.K. participated in writing introduction, discussion and data collection. U.B. participated in writing postsurgical orthodontic treatment, discussion and data collection. J.H.J. conceived of the study, and participated in its design and coordination and helped to draft the manuscript. All authors read and approved the final manuscript.

\section{Consent for Publishing Photographs}

Written informed consent was obtained from the patients for publication of this article and accompanying images.

\section{Conflict of Interest}

No potential conflict of interest relevant to this article was reported.

\section{References}

1. Sillence DO, Senn A, Danks DM. Genetic heterogeneity in osteogenesis imperfecta. J Med Genet 1979;16:101-16.

2. Marini JC, Forlino A, Cabral WA, Barnes AM, San Antonio JD, Milgrom S, et al. Consortium for osteogenesis imperfecta mutations in the helical domain of type I collagen: regions rich in lethal mutations align with collagen binding sites for integrins and proteoglycans. Hum Mutat 2007;28:209-21.

3. Körkkö J, Ala-Kokko L, De Paepe A, Nuytinck L, Earley J, Prockop DJ. Analysis of the COL1A1 and COL1A2 genes by PCR amplification and scanning by conformation-sensitive gel electrophoresis identifies only COL1A1 mutations in 15 patients with osteogenesis imperfecta type I: identification of common sequences of null-allele mutations. Am J Hum Genet 1998;62:98-110.

4. Tournis S, Dede AD. Osteogenesis imperfecta: a clinical update. Metabolism 2018;80:27-37.

5. Rosén A, Modig M, Larson O. Orthognathic bimaxillary surgery in two patients with osteogenesis imperfecta and a review of the literature. Int J Oral Maxillofac Surg 2011;40:866-73.

6. Smith R. Osteogenesis imperfecta: the brittle bone syndrome. Nurs RSA 1987;2:17-23, 40.

7. O'Connell AC, Marini JC. Evaluation of oral problems in an osteogenesis imperfecta population. Oral Surg Oral Med Oral Pathol Oral Radiol Endod 1999;87:189-96.

8. Schwartz S, Tsipouras P. Oral findings in osteogenesis imperfecta. Oral Surg Oral Med Oral Pathol 1984;57:161-7.

9. Chang PC, Lin SY, Hsu KH. The craniofacial characteristics of osteogenesis imperfecta patients. Eur J Orthod 2007;29:232-7.

10. Waltimo-Sirén J, Kolkka M, Pynnönen S, Kuurila K, Kaitila I, Kovero O. Craniofacial features in osteogenesis imperfecta: a cephalometric study. Am J Med Genet A 2005;133A:142-50.

11. Aizenbud D, Peled M, Figueroa AA. A combined orthodontic and surgical approach in osteogenesis imperfecta and severe Class III malocclusion: case report. J Oral Maxillofac Surg 2008;66:104553.

12. Tashima H, Wattanawong K, Ho CT, Wen-Ching-Ko E, Nguyen A, Lo LJ. Orthognathic surgery considerations for patients with undiagnosed type I osteogenesis imperfecta. J Oral Maxillofac Surg 2011;69:2233-41.

13. Ormiston IW, Tideman H. Orthognathic surgery in osteogenesis imperfecta: a case report with management considerations. J Craniomaxillofac Surg 1995;23:261-5.

14. Cole NL, Goldberg MH, Loftus M, Kwok V. Surgical management of patients with osteogenesis imperfecta. J Oral Maxillofac Surg 1982;40:578-84.

15. Morton ME. Excessive bleeding after surgery in osteogenesis imperfecta. Br J Oral Maxillofac Surg 1987;25:507-11.

16. Bell RB, White RP Jr. Osteogenesis imperfecta and orthognathic surgery: case report with long-term follow-up. Int J Adult Orthodon Orthognath Surg 2000;15:171-8.

17. Keegan MT, Whatcott BD, Harrison BA. Osteogenesis imperfecta, perioperative bleeding, and desmopressin. Anesthesiology 2002;97:1011-3.

18. Kindelan J, Tobin M, Roberts-Harry D, Loukota RA. Orthodontic and orthognathic management of a patient with osteogenesis imperfecta and dentinogenesis imperfecta: a case report. J Orthod 2003;30:291-6. 
19. Lindahl K, Langdahl B, Ljunggren Ö, Kindmark A. Treatment of osteogenesis imperfecta in adults. Eur J Endocrinol 2014;171:R7990.

20. Eghbali-Fatourechi G. Bisphosphonate therapy in pediatric patients. J Diabetes Metab Disord 2014;13:109.
How to cite this article: Kim DY, Baik U, Jeon JH. Osteogenesis imperfecta and combined orthodontics and orthognathic surgery: a case report on two siblings. J Korean Assoc Oral Maxillofac Surg 2020;46:70-77. https://doi.org/10.5125/jkaoms.2020.46.1.70 